\title{
Thyroid function in very low birthweight infants after intravenous administration of the iodinated contrast medium iopromide
}

\author{
J Dembinski, V Arpe, M Kroll, G Hieronimi, P Bartmann
}

\begin{abstract}
Background-Thyroid function disorders have often been observed in preterm infants after intravenous administration of iodinated contrast medium. The effect on thyroid function depends on the dosage, but the choice of the contrast medium may be equally important, as there are appreciable pharmacological differences between them.

Method-Thyroid function was analysed in 20 very low birthweight infants of gestational age less than 30 weeks after injection of iopromide, a monomeric nonionic iodinated contrast medium. Levels of free thyroxine and thyroid stimulating hormone were compared with those in $\mathbf{2 6}$ control infants.

Results-Free thyroxine levels in all study infants ranged from 9.0 to $25.7 \mathrm{pmol} / 1$ (days 14-21) and 9.0 to $23.2 \mathrm{pmol} / 1$ (days 35-49), and thyroid stimulating hormone levels ranged from 0.13 to $0.26 \mathrm{mU} / 1$ (days 14-21) and 0.26 to $11.11 \mathrm{mU} / 1$ (days 35-49). These levels were not altered after injection of iopromide.

Conclusion-The risk of transient hypothyroidism or hyperthyrotropinaemia may be reduced with the use of iopromide compared with other contrast media.
\end{abstract} (Arch Dis Child Fetal Neonatal Ed 2000;82:F215-F217)

Keywords: preterm infants; iodine; iopromide; thyroid function; thyroxine; contrast medium

In the neonatal intensive care unit, non-radioopaque central silastic catheters are commonly used for parenteral nutrition. Intravenous application of iodine-containing contrast medium for radiographic imaging may lead to hyperthyrotropinaemia or hyperthyroidism. ${ }^{1-4}$ The blockade of iodide absorption by the thyroid gland, known as the Wolff-Chaikoff effect, ${ }^{5}$ has been assumed to be partly responsible for the alterations in thyroid function. Very low birthweight (VLBW) infants are highly susceptible to alterations in thyroid function caused by iodine exposure. ${ }^{6}$ Thyroid function during the neonatal period is critical for neurological development and metabolism. Thus it is advisable to avoid exposure of preterm infants to iodine whenever possible. However, a high proportion of these infants require parenteral nutrition through central silastic catheters, and reliable radiographic imaging of percutaneous non-radio-opaque silastic catheters can only be achieved by using contrast medium. The minimal load of iodine (free iodide) that is safe with respect to thyroid function is not clear in VLBW infants. The contrast medium used in preterm infants should achieve the optimal relation between iodide load and radiographic quality. Thus the choice of medium could be important to minimise the risk of thyroid complications. We describe the effect of iopromide, a non-ionic monomeric contrast medium with a relatively low iodide delivery rate, ${ }^{7}$ on thyroid function in VLBW preterm infants.

\section{Methods}

Iopromide is used for diagnostic imaging of non-radio-opaque central silastic catheters in our neonatal intensive care unit. Thyroid function is routinely monitored in all VLBW infants by determination of free thyroxine (T4) and thyroid stimulating hormone (TSH). We analysed hormone levels of 20 consecutive VLBW infants after intravenous administration of $0.3-$ $1.0 \mathrm{ml}$ of the water soluble contrast agent iopromide (Ultravist) containing $300 \mathrm{mg} / \mathrm{ml}$ iodine in a $2: 10.9 \% \mathrm{NaCl}$ or distilled water dilution. After injection of the contrast medium at 4-10 days of age, free T4 and TSH were measured at two weeks (days 14-21) and six to seven weeks (days 35-49) of age. These values were compared with those for 26 age and weight matched premature infants without central lines who served as controls. Table 1 gives morbidity and frequency of dopamine treatment in the two groups.

Neonatal infection was diagnosed by clinical symptoms and $\mathrm{C}$ reactive protein $>1.0 \mathrm{mg} / \mathrm{dl}$ and/or interleukin $8>65 \mathrm{pg} / \mathrm{ml}$, and/or immature/total neutrophils (ITQ) $>0.25$. Definition of bronchopulmonary dysplasia was $\mathrm{O}_{2}$ supplementation and/or ventilation on day 28. Perinatal asphyxia was considered if umbilical arterial cord $\mathrm{pH}$ was below 7.1 and clinical symptoms occurred. Intrauterine growth retardation was diagnosed if birth

Table 1 Clinical characteristics of 46 very low birthweight preterm infants

\begin{tabular}{|c|c|c|}
\hline & $\begin{array}{l}\text { Group I } \\
(n=26)\end{array}$ & $\begin{array}{l}\text { Group II } \\
(n=20)\end{array}$ \\
\hline Mean gestational age (weeks) & 28.8 & 28.3 \\
\hline Mean birth weight $(\mathrm{g})$ & 1115.0 & 965.0 \\
\hline Asphyxia (IVH $\geqslant$ II) & 3 & 5 \\
\hline BPD & 4 & 9 \\
\hline INF & 18 & 16 \\
\hline Dopamine & 5 & 9 \\
\hline SGA & 0 & 5 \\
\hline
\end{tabular}

Group I, controls; Group II, intravenous iopromide. BPD, bronchopulmonary dysplasia; INF, neonatal infection; SGA small for gestational age; IVH, intraventricular haemorrhage small for gestational age; IVH, intrave
(graded according to Papile, et $a l^{14}$ ). 


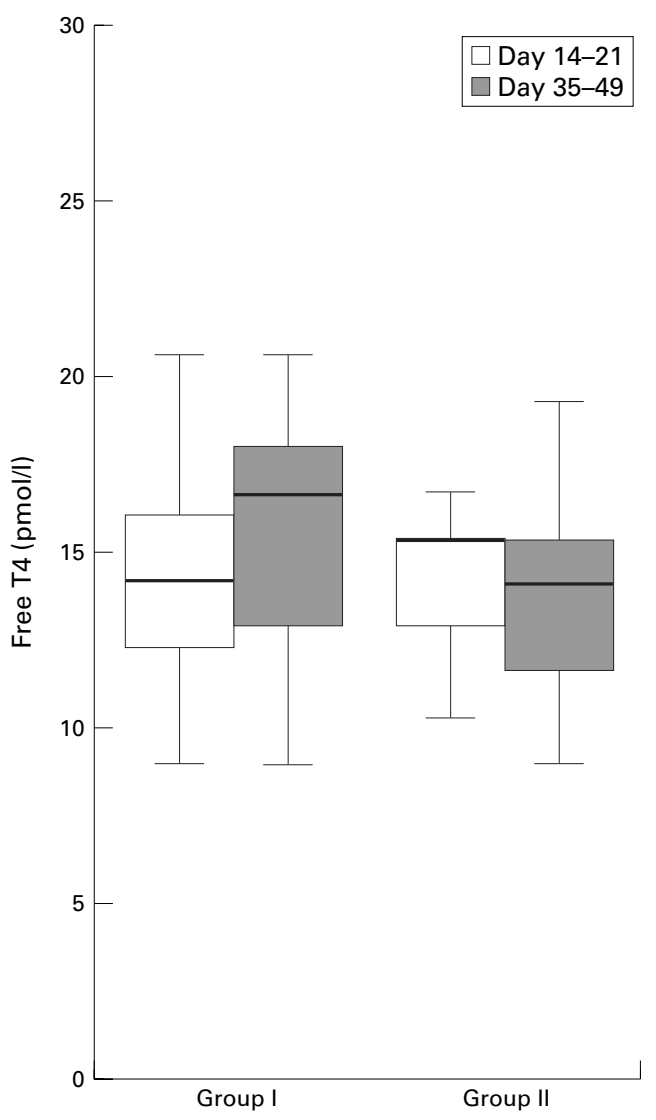

Figure 1 Plasma free thyroxine (T4) concentrations in controls (Group I) and after intravenous administration of iopromide (Group II). Median values and quartiles are shown. Differences are not significant $(p>0.05)$.

weight was below the 10 th percentile. Infants with chromosomal anomalies, complex dysmorphology, or cyanotic cardiac defect were excluded.

All mothers of infants studied had clinically normal thyroid function. Blood transfusions were given as red packed cells exclusively not less than 24 hours before blood sampling. Blood samples were taken by either arterial or venous puncture. Free T4 und TSH were determined by commercial assays (free T4, AxSYM Free T4, Abbott, Weisbaden, Germany; TSH, hTSH Ultrasensitiv II, Abbott).

Differences between the two groups were tested for significance by use of the Wilcoxon test carried out with SSPS 8.0 (significance assumed at $\mathrm{p}<0.05$ ).

\section{Results}

Table 1 shows the clinical characteristics of the infants studied. The two groups did not differ significantly with respect to gestational age (28.3 $v 28.8$ weeks). Neonatal morbidity was higher in those infants who had received iopromide. No infant showed congenital hypothyroidism. Newborn screening results for TSH obtained on days 3-5 were within the normal range in all infants.

On days $14-21$, free $\mathrm{T} 4$ in all infants ranged between 9.0 and 25.7 (median 14.2) pmol/1, and on days 35-49 between 9.0 and 23.2 (median 14.2) pmol/1. Levels of free T4 were unchanged between 14 and 21 and 35 and 49

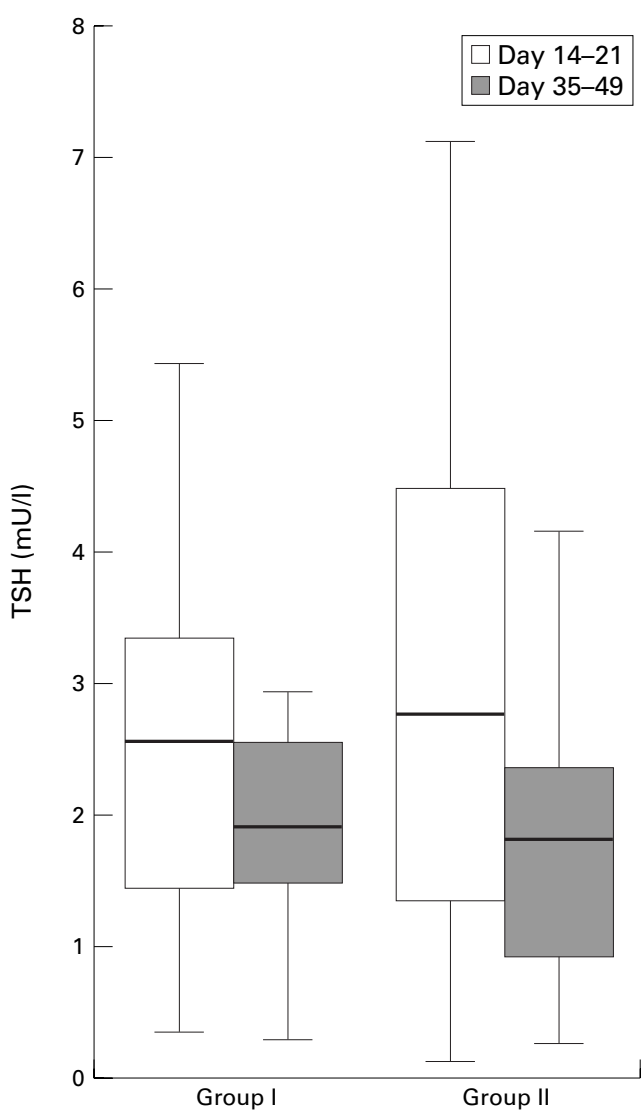

Figure 2 Plasma thyroid stimulating hormone (TSH) in controls (Group I) and after intravenous administration of iopromide (Group II). Median values and quartiles are shown. Differences are not significant $(p>0.05)$.

days in both groups. Free T4 values for the infants who had received iopromide showed no statistically significant differences from those for the control infants on days 14-21 and 35-49 (fig 1).

TSH levels ranged between 0.13 and 7.36 $\mathrm{mU} / 1$ on days $14-21$ and between 0.26 and $11.11 \mathrm{mU} / 1$ on days $35-49$. They were lower in both groups on days 35-49, but differences were not statistically significant. Slightly increased TSH levels were observed at 14-21 days of age after iopromide treatment (median $2.57 v 2.76 \mathrm{mU} / \mathrm{l}$ ), but again the difference did not reach statistical significance. TSH levels in the two groups were not statistically significantly different on days 35-49 (median $1.90 v$ $1.82 \mathrm{mU} / \mathrm{l}$ ) (fig 2).

\section{Discussion}

The biologically effective load of free iodide depends on the status of thyroid maturation and on the chemical form and breakdown of the contrast medium. At a gestational age of less than 36 weeks, thyroid follicular cells are unable to modify iodide uptake by autoregulation..$^{8-10}$ This leads to an increased risk of hormone synthesis being blocked (Wolff-Chaikoff effect) as a consequence of high intracellular iodide concentration following iodine exposure. ${ }^{5}$ Degradation of iopromide produces about $0.06 \mathrm{mg}$ of free readily absorbable iodide $/ 100 \mathrm{ml}$ contrast medium. Other contrast media deliver between $0.18 \mathrm{mg}$ 
iodide $/ 100 \mathrm{ml}$ (Omnipaque) and $0.4 \mathrm{mg}$ iodide $/ 100 \mathrm{ml}$ (Hexabrix). Ares et al described hypothyroidism after injection of less than $1 \mathrm{ml}$ Hexabrix 320 (ioxaglinacid containing $320 \mathrm{mg}$ iodine $/ \mathrm{ml}$ ) in 13 premature infants of less than 34 weeks gestational age. They found undetectable free T4 levels in one case. Frequent alterations in thyroid function with decreased tri-iodothyronine, $\mathrm{T} 4$, and free $\mathrm{T} 4$ without the expected increase in TSH were detected in the other infants.

Parravicini et $a l^{1}$ documented transient hyperthyrotropinaemia and transient hypothyroidism resulting from exposure to both contrast medium $(0.3 \mathrm{ml} \mathrm{30 \%} \mathrm{iopamidol)} \mathrm{and}$ skin antiseptic. In their study, small for gestational age infants had increased TSH levels compared with appropriate for gestational age infants, probably reflecting accelerated maturation of hypothalamic-pituitary function after intrauterine growth retardation. A quarter of the preterm infants in our study who had received contrast medium were small for gestational age, and such infants have been reported to show a pronounced increase in TSH levels after exposure to iodine. ${ }^{1}$ Thus we would have expected an accentuation of the effect of exposure to iopromide in our study, which was not evident. For routine local skin disinfection, iodide-containing disinfectant and chlorhexidine was used in both groups.

Dopamine inhibits TSH secretion in vivo and reduces mRNA transcription for $\alpha$ and $\beta$ subunits in vitro. ${ }^{11}$ It inhibits adenylate cyclase, but its definitive molecular mode of action in TSH secretion is not known. In sick infants, suppression of TSH secretion by dopamine has been observed. ${ }^{12}{ }^{13}$ In our study, dopamine treatment was more common in infants who had received iopromide than in the controls (45\% v 19\%). However, dopamine treatment had been discontinued before thyroid testing, and there was no correlation between TSH levels and dopamine treatment within the control group. Thus it is unlikely that dopamine treatment had any effect on the TSH results.

\section{CONCLUSION}

We did not detect hypothyroidism or hyperthyrotropinaemia 4-45 days after injection of iopromide. Therefore iopromide may be superior to other contrast media with regard to thy- roid function in VLBW infants within the above mentioned dose ranges. Nevertheless, in assumed neonatal thyrotoxicosis, the indication for iodine administration should consider the risk of metabolic deterioration. In our study, the different morbidity and frequency of dopamine treatment between the two groups may have masked differences in thyroid function. A controlled prospective study on the effect of different contrast media in VLBW infants is necessary to compare their effects and to verify the potential advantages of iopromide. However, for routine purposes, monitoring of thyroid function would seem to be advisable and may be even more important when other contrast media are used.

1 Parravicini E, Fontana C, Paterlini G, et al. Iodine, thyroid function, and very low birth weight infants. Pediatrics 1996;98:730-4

2 Ares S, Pastor I, Quero J, Morreale de Escobar G. Thyroid complications, including overt hypothyroidism, related to the use of non-radiopaque silastic catheters for parenteral feeding in prematures requiring injection of small amounts of an iodinated contrast medium. Acta Paediatr 1995;84:579-81.

3 L'Allemand D, Grüters A, Beyer P, Weber B. Iodine in contrast agents and skin desinfectants is the major cause for trast agents and skin desinfectants is the major cause for hypothyroidism in premature

4 Saule H, Preissler E, Frasch W, Adams G. Iodine burden in premature infants in roentgenologically controlled positioning of central venous silastic catheters. Monatsschrift Kinderheilkunde 1986;134:21-4.

5 Wolff J, Chaikoff IL. The inhibitory action of excessive odide upon the synthesis of diiodotyrosine and of thyroxine in the thyroid gland of the normal rat. Endocrinology 1948;43:174-9.

6 Smerdely P, Lim A, Boyages SC, et al. Topical iodinecontaining antiseptics and neonatal hypothyroidism in very-low-birthweight infants. Lancet 1989;16:661-4.

7 Jung F, Schmitt RM, Scheller B, et al. Flow rates of roentgen contrast media of different viscosity in 4.1 Charriere contranary catheters. Z Kardiol 1996;85:537-42.

8 Fisher DA. Endocrinology of fetal development. In: Wilson JD, Foster DW, Kronenberg HM, Larsen PR, eds. Williams textbook of endocrinology. Philadelphia: WB Saunders, 1997:1273-302.

9 Sherwin JR. Development of regulatory mechanisms in the thyroid: failure of iodide to suppress iodide transport activity. Proc Soc Exp Biol Med 1982;169:458-62.

10 Castaign H, Fournet JP, Leger FA, et al. Thyroid of the newborn and postnatal iodine overload. Archives Francaises de Pediatrie (Paris) 1979;36:356-68.

11 Shupnik MA, Greenspan SL, Ridgway EC. Transcriptional regulation of thyrotropin subunit genes by thyrotropinreleasing hormone and dopamine in pituitary cell culture. f Biol Chem 1986;261:12675-9.

12 Van den Berghe G, De Zegher F. Anterior pituitary function during critical illness and dopamine treatment. Crit Care Med 1996:24:1580-90.

13 Van den Berghe G, De Zegher F, Lauwers P. Dopamine suppresses pituitary function in infants and children. Crit Care Med 1994;22:1747-53.

14 Papile LA, Burstein J, Burstein R, Koffler H. Incidence and evolution of subependymal and intraventricular haemorrhage: a study of infants with birth weights less than 1500gm. F Pediatr 1978;92:529-34. 